\title{
The Effect of Taxes on Investment: Albanian Case
}

\section{Mergleda Hodo}

\author{
Research assistant in Department of Banking and Finance \\ Epoka University Tirane, Albania. \\ Email:mhodo@epoka.edu.al
}

Doi:10.5901/ajis.2013.v2n11p116

\begin{abstract}
This paper observes the effectiveness of any taxation system, the measurement of the effective tax rate on profitability investment and its implementation on Albania. Focusing on the taxation system, there are going to be some analysis and studies of the actual Albanian tax system and on the other side give information about the domestic and foreign investment in our country. The businesses are always under pressure from the tax system or any government fiscal policy. The estimated model will be offered by all fundamentals of regression analyzes which will identify the relation between the total investment (in $\%$ of GDP) in Albania and the tax rates (as percentage of profit) in order to show if there is any correlation between those two variables. All the data's are taken by World Bank and INSTAT for the period of 2000 to 2012. After reasonable analysis of pros and cons on any effectible side, they will demonstrate that there is weak relationship between the total investment and tax rate in Albania.
\end{abstract}

Keywords: Tax system, business, investment

\section{Introduction}

The effect of taxes on investment is an important topic that has triggered so much discussion and research in economics and finance. Tax policies affects a wide range of economic decision for instance in the short run to stimulate business investment and in the long run, the taxation of income from capital can provide the revenues needed to fund government, but may depress capital formation, output, and consumption. This paper consists in an overview of the Albanian tax system and policies, and also to an overview of the Albanian business environment and how is it affected by the tax policies. In addition it covers some discussions on the Albanian tax system, advantages of the flat tax and some discussions on some changes that can be done in the tax system in order to be more profitable for the state but by protecting the judicial and physical person. It will concentrate in the Small medium enterprises and the foreign direct investment by mentioning with values their distribution in sectors and also their trend in period of time.

The paper will measure the effect of taxes using new data and an original methodology. The estimated model will be presented by all fundamentals of regression analyzes which will show the relationship between the tax rates and the total investment in Albania, it is going to show if there is any correlation between those two variables. And from this study, some results come out and the conclusion of all the analysis is going to be discussed as well.

\section{Literature Review}

One of the major public policy issues in recent years are the tax changes. The tax cuts of 2001 and 2003 were passed among firestorms of debate about their likely effects. According to policymakers, the tax cuts would both stimulate the economy in the short run and increase normal output in the long run. The academic literature has demonstrate that the factors affect the taxes are often correlated with other developments in the economy and they get the result that there exist a negative effect between taxes and investment.

"The result of tax competition may well be a tendency toward less than efficient levels of output of local services. In an attempt to keep taxes low to attract business investment, local officials may hold spending below those levels for which marginal benefits equal marginal costs, particularly for those programs that do not direct benefits to local business" (Oates 1972,)

Albert Einstein said "the hardest thing in the world to understand is the income tax. 
"As taxes increased from fairly low levels, tax revenue received by the government would also increase. However, as tax rates rose, there would come a point where people would not regard it as worth working so hard. This lack of incentives would lead to a fall in income and therefore a fall in tax revenue. The logical end-point is with tax rates at 100\% where no one would bother to work (understandably!) and so tax revenue would become zero."(The Laffer curve) ${ }^{1}$

\section{Actual Tax System in Albania}

In 1991 the Albanian economy changed from a centrally planned economy system to a free- market system. In that period, government providing for the protection of private property, foreign investments, is legalizing private employment of workers, privatization of state property, and the extension and acceptance of credit. Also government officials set to work drafting a new civil code, a revised commercial code, new enterprise laws, and new banking, tax, labor, antitrust, and social security legislation. Conversely for the moment Albanian economic growth has changed significantly. The government's intervention to reduce the informal employment through changes the tax regime and social welfare system will have a considerable effect, particularly among low- income earners. For the moment, the Albanian taxation system consists in the usage of flat tax for consumption and income taxes. This flat tax is 20 percent (\%) for the consumption and 10 percent (\%) for the income. Albania applies the lowest tax rate in the region, obviously the Albanian government adopted this tax system from other countries but it had a good impact in decreasing the informal economy, increasing the economic activity and as consequences it generated FDI reduction in tax evasion. The flat tax is a fiscal instrument which makes an equal treatment for all, that emphasizes the approach that everyone is equal in front of the law and should be treated in the same way by the government.

Corruption has always been a problem for the developing countries such as Albania and the flat tax has decreased the opportunities for fraud on taxes and has increased the incentives for economic activities. This is interpreted as more saving in the Albanian budget, high revenues and as the economic activities are increased also the consumption is increased. As it is mention above this system of flat tax rate is the same for all ,but the question arises if is it fair to be treated equal the rich and the poor individual, thinking that this system may punish the poor people it is needed to be analyzed more in details. But even in this point there is a dilemma in the categorization of the rich and poor people as there is no any fixed definition for the poorness and richness. The first thing to be done is to eliminate the tax evasion and then determining a minimum income level in order to put a zero \% tax on this min income level and then making the categorization according to the level of income. Another effect of flat tax is that it also removes the progressivity from the system of tax eliminating the taxation redistribution, even though the redistribution effect from the taxation system has not been very useful in many countries. In the Albanian tax system the legal and physical persons are subject to profit tax $(10 \%)$, personal income tax (10\%), withholding tax(10\%) and VAT (20\%).

When the government decides about the taxation system it is important to take into consideration the demand for public services, the political conditions, the development level of Albania, because the main aim of a tax system is to generate as much profits as possible in order to support the government spending and to finance more in the public sector. The system of taxation in a country doesn't show only its values but also the fairness and the power of the government. Albania is a small country and it has limited sources of revenues, the main source is the current account, especially the exports, for that reason the trade tax is very account as it makes up a considerable percentage of the tax revenues. We as a country rely more on the excise taxes, because direct taxes like VAT require more effective tax administration in order to generate profit. ${ }^{2}$

\subsection{Flat tax or progressive tax in Albania}

The implementation of the flat tax has had an impressive impact on economy. Registration of the businesses brings more benefits for the economy than before. Developing countries apply this tax system since they've certain specification as the level of informality and have not consolidated fiscal system. Flat tax, as progressive tax has their advantages and disadvantages.

\footnotetext{
1 The Laffer Curve is aptly named after Professor Art Laffer. It is a representation of the relationship between possible rates of taxation and the resulting levels of government revenue. It illustrates the concept of taxable income elasticity-i.e., taxable income will change in response to changes in the rate of taxation.

${ }^{2}$ Albania Fiscal Policy: Designing Tax Policy by Given Circumstances, Fatbardha Kadiu, Vol. 3 (1) January 2012
} 
An important argument in favor of progressive tax could be social equality, which practically means the rich people are not rich enough to have power over the poor people. Progressive taxation serve on redistribution policies but not in productivity, where revenue in the economy transferred to unskilled workers and thus reduce the incentives to accumulate capital from individuals, innovative companies or financial opportunities to invest and open new locations working. Because of 50 years of communism, Albania has a need to increase human and physical capital more than anything else! Also is necessary the separation between politicians, who are concerned in the cake distribution and consequently in the vote, who are more interested in making a larger cake. Politicians have two choices to make, with consequences for economic growth. If you see the typical voter as poor, the choice that can maximize the number of votes is to increase tax rates for entrepreneurs, businesses and banks later this wealth redistribution. On the other hand, if you believe that economic growth and economic stability is more important in the long run, they will impose lower taxes that help in the growth of productive capital, which then brings new jobs. But the contradictions in this system is that it can maximize votes cannot bring economic growth!

It is important to mention that the progressive tax is productive for the state-budget and flat tax consider favorable for businesses. If we refer to the time when the flat tax was implemented in Albania, immediately, in the short period began to feel the effects of economic crises and the anticipated effects of this tax were not those expected to be, because it have to take in consideration the changes that Albanian economy faced as the result of global crises. The flat tax is the main fiscal instrument when Prime Minister, diplomat, pay fees equivalent to unemployed, invalid, the orphan or the ones who sells seeds on the road, taxed with the same tax fee, as a factory owner ferry air agency but this is not accurate. Also it favors the foreign direct investment but not the domestic investment.

Changing the fiscal policy in Albania by renunciation of the flat tax and application of the progressive system is assessed from two perspectives in Albanian economy. According to many economists, the Albanian economy leaves spaces for the application of progressive tax, but the manner of its application should be well studied.

The computations of Sen's welfare index and Gini inequality index display that no significant changes occur for all the scenarios we stimulated. The inequality index is higher in 2005 than in 2008 and this implies higher social welfare too. Nevertheless, the only scenario that would improve welfare index is progressive tax rule as before 2007. As conclusion, a kind of progressivity should be back in the taxation rule without affecting the attractiveness of the simplicity of a flat tax entails.

\section{Albanian Investment Environment}

During the last years Albania has faced a considerable economic shift as the agriculture and the outdated industry has been replaced by construction service field of the investment and they are the main contributors in the Albanian GDP. The increase in the privatization and on FDI also the current account is increased as increase in exports. In $2008-2009$ the Albanian economy has also been affected by the current financial crises but it was not a very huge effect due to the decrease in the public spending. Albania had a positive trend during 2010 and first quarter of 2011 as it was stated by the data from Bank of Albania (BOA). This economic growth has been mainly supported by the foreign and domestic investment. The running of new domestic businesses has been low due to the increase in the interest rates and this had a tightly effect in the budget deficit.

Figure1: Sectoral distribution of Small Medium Enterprises (SME) (\% of trade)

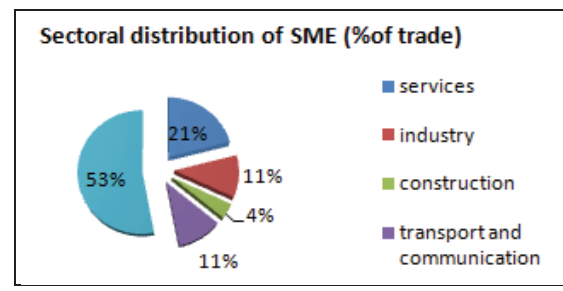

As we see from the graph above the SME in Albania are spread in almost all the business sectors and in the most important sectors. The highest percentage of the SME operate in the trade sector which is for the Albanian economy a very important sector while the generation of the revenues and this logically means that the SME has a very strong impact on the Albanian overall economy performance and in the overall Albanian GDP. Albania is a country that has been 
under communism regime and it was the last country in the south - eastern Europe that implemented the free market after the 1990 and directly after that, it started to adapt the SME ,but as a country with lack of culture in voluntary compliance of tax, there were a lot of incentives for the operation in informal economy .Despite this fact, the Albanian market is dominated from SME, so those enterprises are very important factor to be considered by the taxation policy maker.

Figure 2: FDI (Foreign direct investment), net inflows

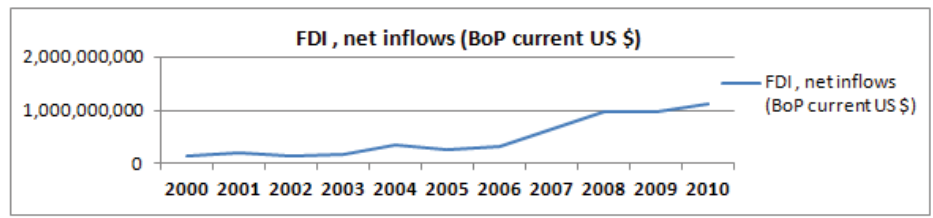

Source: World Bank

Here is a survey of the trend of the FDI net inflows in Albania from the year 2000 to 2010,we can obviously see that there is a positive trend that has been increasing by reaching its peak in 2010,this means that there is also been an increase in the GDP. We can easily say that the FDI in Albania has not been affected by crises, it increased by $23 \%$ compared to 2009 reaching the level of 837 million in 2010 that is more than double of the FDI in Albania in 2006. The FDI has been attracted mostly by the increase in the privatization percentage in different sectors such as energy, telecommunication, banking etc. The privatization percentage arises $26 \%$ in 2009.

\section{Methodology}

In this study is going to investigate relation between the total investment (\% of GDP) and the tax rates (as percentage of profit) in Albania in order to see the effect of the tax rate on both foreign and domestic investment. The regression model is run over 13 years from 2000 QII to 2012 QII because of the data being more reliable in these years ${ }^{3}$. According to ISLM framework, an increase in taxes lowers consumption by reducing disposable income. It raises investment by reducing the real interest rate. Changes in net exports may also alleviate the effect of a tax increase. The decreases in interest rate tend to cause the dollar to depreciate, and so raises net export. Conversely, the disposable income effect controls the interest rate and exchange rate effects, so tax increases are on net contradictionary.

Other models suggest that tax increases could raise consumption and investment by creating expectations of lower interest rates and smaller government expenditures ${ }^{4}$.

Figure 3: The graph of the curbs of total tax rate, total investment

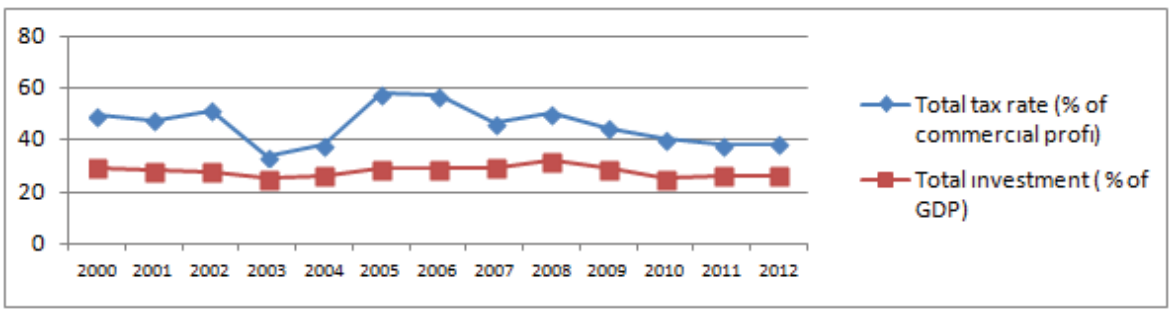

Source: INSTAT, World Bank

\footnotetext{
${ }^{3}$ The data are taken by World Bank and INSTAT

${ }^{4}$ Giavazzi and Pagano (1990)
} 


\subsection{Regression analysis}

Following the graph as in figure 3 , the relation between tax rate and investment is weak for Albanian economy through the years 2000-2012. It has been analyzed the regression between total tax and total investment. Tax rate is the independent value while investment is taken as dependent.

The Regression equation is:

$Y=\alpha+\beta X+e$

Where:

$Y$ - is the depended variable, which is being predicted or explained, in this case the investments.

$\boldsymbol{\alpha}$ - is the expected intercept parameter, equals the value of $Y$ when the value of $X=0$.

$\beta$ - is the expected slope, how much $Y$ changes for each one-unit change in $X$.

$X$ - is the independent or explanatory variable, in this case tax rate.

$\mathbf{e}$ - is the error term; the error in predicting the value of $Y$, given the value of $X$ (it is not displayed in most regression equations).

It is visible that tax rate in fact expected a negative effect on investment ${ }^{5}$. The equation of regression between investment being the dependent variable and tax rates being the independent variable is as follows: $i=19.312+0.19 \pi$

Where $i$ represents investment which are trying to be predicted or explained by $\pi$ which represents tax rate. The intercept would represent the value of investment if tax rate was equal to 0 . Slope in this case is 0.19 ; this would be understood as a level of correlation between variables. It extensively explains at what level is tax rate influencing investment. This result may be influenced at some level by the changes of tax rates occurring in 2007. In that time correlation between the two variables is surprisingly weak giving further support to the EY General Equilibrium Model in the long-run. As for the statistical significance, $t$-statistics is going to be studied. $t$ - statistics $=7.427$, that is bigger than 5 , it means that the $b$ coefficient is statistically significant, furthermore, means that the independent variable or $X$, i.e. tax, should be kept in the regression equation, since it has a statistically considerable relationship with the dependent variable or investment.

Finally explanatory meanings of the statistics found will be tested. In this part, how much of a variable inside the equation, i.e. the dependent variable or investment can be explained by a change in the other variable i.e. independent variable or tax rate. This is given statistically by $R^{2}$ also known as determination coefficient. In this formula, $R^{2}$ is equal to $0.717>0.5$. In this case only $72 \%$ of the change in investment can be explained by a change in tax rate. This concept can be easier to understand in this way; for every point increase in tax rate, investment would increase by a multiplier of 0.717 . What can be seen is that investment move slower but in the same direction as interest rate. If there is a change in taxes, then according to the figures in Albania during this period of time, a change somewhat smaller in investment would be expected.

\section{Conclusion}

According to the studies done with data it is conducted empirically that taxes have weak effect on investment, which means that the change in the tax rate lead to changes in the investment. Investment behavior is persuaded by taxes while low taxes favor it, especially within a context of cross- border direct investment. High taxes effect negatively the economic growth of country but the flat-tax regime in Albania feeds economic growth encouraging the production of capital and attracts foreign investments through the increase of the investment capacity in the economy. Strengthening property rights, improving contract enforcement, and simplifying the tax system would encourage investment and medium-term growth.

\section{References}

Christina D.Romer, David H.Romer, November 2006 "The Macroeconomic Effects of Flat Tax Changes: Estimates Based on a New Measure of Fiscal Shocks"

Daniel Dreßler "The Impact of Corporate Taxes on Investment: An explanatory Empirical Analysis for Interested 
Practitioners."Discussion paper No.12-040

Edlira Narazani ,Isilda Mara "The effects of Flat Tax on Inequality and Informal Employment: The case of Albania" Fatbardha Kadiu "Albania Fiscal Policy: Designing Tax Policy by Given Circumstances" , Vol. 3 (1) January 2012

Organisation for Economic Co-operation and Development, February 2008. "Tax Effects on Foreign Direct Investment".

Richard M. Bird Professor Emeritus of Economics University of Toronto, "Tax Challenges Facing Developing Countries", March 12, 2008 Yoram Margalioth , "Tax competition, Foreign Direct investments growth: using the tax system to promote developing countries" 10 January 2003 